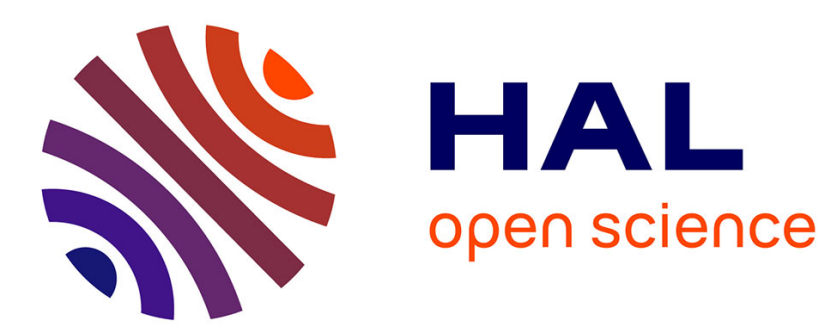

\title{
Optical pumping in strained In0.2Ga0.8As/GaAs quantum wells
}

G. Bacquet, F. Hassen, N. Lauret, J. Barrau, A. Marti-Ceschin, N. Grandjean, J. Massies

\section{> To cite this version:}

G. Bacquet, F. Hassen, N. Lauret, J. Barrau, A. Marti-Ceschin, et al.. Optical pumping in strained In0.2Ga0.8As/GaAs quantum wells. Journal de Physique IV Proceedings, 1993, 03 (C5), pp.C5-319C5-322. 10.1051/jp4:1993565 . jpa-00251652

\section{HAL Id: jpa-00251652 https://hal.science/jpa-00251652}

Submitted on 1 Jan 1993

HAL is a multi-disciplinary open access archive for the deposit and dissemination of scientific research documents, whether they are published or not. The documents may come from teaching and research institutions in France or abroad, or from public or private research centers.
L'archive ouverte pluridisciplinaire HAL, est destinée au dépôt et à la diffusion de documents scientifiques de niveau recherche, publiés ou non, émanant des établissements d'enseignement et de recherche français ou étrangers, des laboratoires publics ou privés. 


\title{
Optical pumping in strained $\operatorname{In}_{0.2} \mathrm{Ga}_{0.8} \mathrm{As} / \mathrm{GaAs}$ quantum wells
}

\author{
G. BACQUET, F. HASSEN, N. LAURET, J. BARRAU, A. MARTI-CESCHIN* ${ }^{*}$, N. GRANDJEAN* \\ and J. MASSIES ${ }^{*}$
}

Département de Physique, UA 074 du CNRS, INSA, avenue de Rangueil, 31077 Toulouse cedex, France

${ }^{*}$ Laboratoire de Physique du Solide et Energie Solaire, CNRS, 06560 Valbonne, France

\begin{abstract}
Spin orientation by optical pumping experiments were undertaken on three strained Ino.2Ga0.8As/GaAs QW's with different thicknesses. The results concerning the circular degree of polarization dependence on the exciting energy are very different from well to well. This indicates that in such systems the hole spin relaxation is incomplete and must be considered in the interpretation of the optical pumping data. We show that the complexity of the situation makes difficult the evaluation of the characteristic times governing the photoluminescence polarization.
\end{abstract}

\section{1) INTRODUCTION}

In strained layer quantum wells (QW's) of $\operatorname{In}_{x} \mathrm{Ga}_{1-x}$ As grown epitaxially on GaAs the combination of both strain and quantum size effects, which have the same sign, lifts the degeneracy of the uppermost $\Gamma_{8}$ valence band. Therefore the heavy hole (hh) band lies above the light hole (lh) one and the splitting between these two bands is large enough to strongly reduce the mixing between $\mathrm{hh}$ and $\mathrm{lh}$ states.

In an optical pumping experiment carriers are optically excited with polarized light and the circular degree of polarization $P$ of the recombining light is measured. This technique was successfully applied to bulk semiconductors[1], undoped or p-doped GaAs/Al $\mathrm{Ga}_{1-\mathrm{x}} \mathrm{As} \mathrm{QW}$ 's[2-4] and

GaAs/AlAs short period superlattices[5]. In these compounds the common and natural assumption of the complete relaxation of the spin of the photogenerated holes[6] allows, from the measure of $P$ and of its decrease under the application of a transverse magnetic field, to determine the lifetime $\tau$ and the spin relaxation time $\mathrm{T}_{1 \mathrm{e}}$ of the photogenerated electrons. Uenoyama and Sham[7] have shown that in n-type GaAs/AlGaAs QW's such an assumption fails completely. In this paper we show that in strained InGaAs/GaAs QW's the hole spin relaxation is incomplete and must be taken into account in agreement with the recent work of Vasil'ev et al.[8].

2) EXPERIMENTAL

The sample used in our experiments was grown by MBE on a (001) oriented substrate at $T_{s}=520 . \mathrm{C}$. It contains three wells of $\mathrm{In}_{0.2} \mathrm{Ga}_{0.8} \mathrm{As}$, the respective widths of which are $7,9,11$ monolayers (ML), separated by $50 \mathrm{~nm}$ thick GaAs barriers.

To fulfill the optical pumping condition, the PL of the sample, immersed in liquid helium and mounted free of extra strain on the holder, was excited 
with $\sigma^{+}$or $\sigma^{-}$circularly polarized light from a tunable titanium:sapphire laser pumped by an $\mathrm{Ar}^{+}$-ion laser. The polarized PL and PLE were detected and analysed with a $0.85 \mathrm{~m}$ Spex double monochromator followed by a cooled GaAs-cathode photomultiplier. For the recording of PLE spectra the detection was set on the low-energy side of the PL line under investigation and the excitation power density was controlled and kept constant (typically 0.3 W. $\mathrm{cm}^{-2}$ ). For Hanle measurements a magnetic field up to $0.75 \mathrm{~T}$ could be applied perpendicularly to the incident light.

3) RESULTS

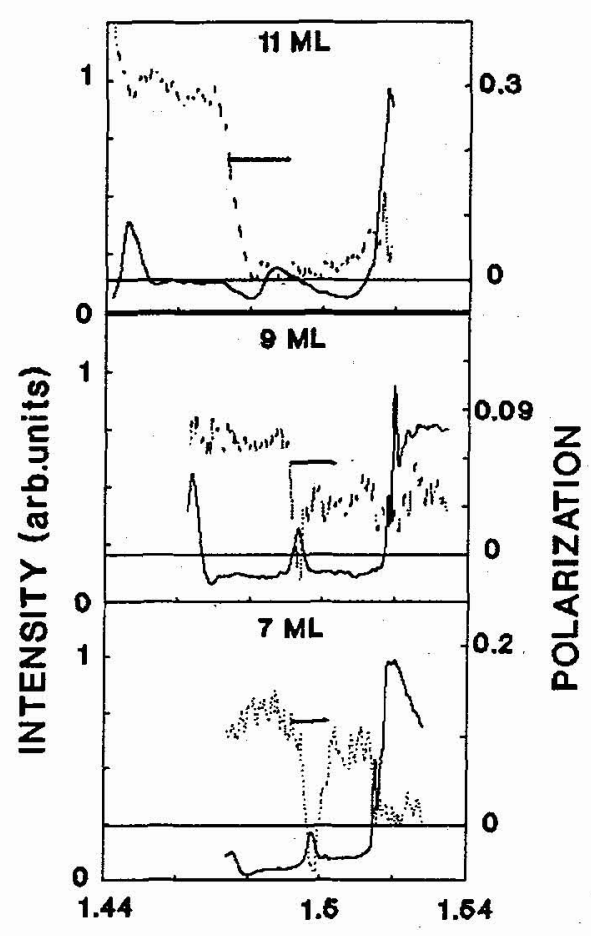

ENERGY (eV)

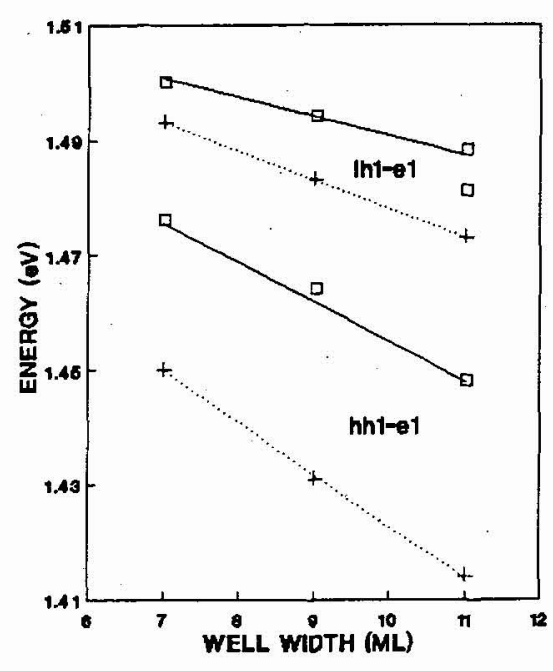

FIG.2:Experimental (squares) and calculated PLE peak positions taking into account (full line) or not $(+)$ the Indium surface segregation.

FIG.1:PLE spectra (left-hand scale) and $P\left(\right.$ h $\left.v_{\text {exc }}\right)$ variations (right-hand scale) of the three studied wells.

In Fig.1 are displayed the PLE spectra (left-hand scale) and the P(hv exc) variations (right-hand scale) of the three wells, the respective PL peak energies are (in decreasing well width): $1.4424,1.4585$ and $1.4736 \mathrm{eV}$. The corresponding Stokes' shifts are 6,4 and $3 \mathrm{meV}$. It must be noted that the overall $P$ (hv $v_{\text {exc }}$ ) dependences are quite different from well to well. Lorentzian depolarization curves were obtained at different $h v_{\text {exc }}$ as well with the 11ML wide well as with the 7ML one, for which the measured $P$ values are high enough to allow Hanle measurements. For the $7 \mathrm{ML}$ well in the excitation energy range (1.48-1.495eV) the Hanle width (determined as $P(\Delta \mathrm{B}) / P(0)=1 / 2$ ) and the $P$ 
value are found to be constant within the experimental uncertainty. Their respective values are $117 \pm 4 \mathrm{mT}$ and $12.5 \pm 2.5 \%$. In Table $I$ are given the Hanle widths and the $P\left(h_{\text {exc }}\right)$ values found with the $11 \mathrm{ML}$ well.

Table I

11ML wide well: Hanle width $(\Delta B)$ and polarization $P$ as a function of the exciting energy hv ${ }_{\text {exc }}$.

\section{4) INTERPRETATION}

\begin{tabular}{|c|c|c|}
\hline hv ${ }_{\text {exe }}(e V)$ & 1.452 & 1.460 \\
\hline$P(\%)$ & $30.5 \pm 2$ & $28 \pm 2$ \\
\hline$\Delta \mathrm{B}(\mathrm{mT})$ & $246 \pm 5$ & $25 \pm 5$ \\
\hline
\end{tabular}

\subsection{Assignation of the PLE transitions}

Theoretical calculations have been made of the various energy separations between the electron states and the heavy and light hole states using the model described by Marie et al.[9] based on deformation potential and elastic theory. The calculation contains no adjustable parameters. The actual potential profile due to Indium surface segregation[10] was taken into account according to the model proposed by Nagle et al.[11]. Only in this case good agreement between experimental and theoretical values is obtained as displayed in Fig.2.

As previously reported in the literature a dip in the $P\left(h v_{\text {exc }}\right)$ dependence, of ten reaching negative values, is associated with the (1lh-le) transition. If in GaAs/AlGaAs QW's the $1 \mathrm{lh}$ level is located in the well, this is not always the case in strained In $\mathrm{Ga}_{1-x}$ As/GaAs QW's. In this system the $11 \mathrm{~h}$ level can be either in the well (type I transition) or in the GaAs barrier (type II transition) according to the valence band configuration. In a previous paper [12] we have shown that optical pumping measurements permitted to characterize the nature of transitions involving lh. A well marked narrow PLE peak and a $P$ (hv ${ }_{\text {exc }}$ ) dip with negative value going together in the spectra of the 7 and 9 ML wide wells allow us to say that the (11h-le) transition is type I in these two wells. The situation is not so clear for the 11ML wide well for which itseems difficult, according to the experimental uncertainty, to precise the exciting energy value (between 1.48 and $1.49 \mathrm{eV}$ ) where the polarization really reaches its lowest value. Two minima separated by $6 \mathrm{meV}$ are associated one with a minimum of the PL intensity (type II transition), the other with a rather broad PLE peak (type I transition). The calculated value lying between the two corresponding exciting energies does not permit us to decide.

\subsection{Comments on the polarization.}

Assuming a complete hole spin relaxation the theory leads to a $P$ value, for an exciting energy greater than that of the (1/h-1e) transition, equal to one half that measured for (llh-le) $>h v \geq(1 \mathrm{hh}-1 \mathrm{e})$. In such a situation the measure of both $\Delta \mathrm{B}$ and $P$ permits one to evaluate $\tau$ and $T_{1 e}$. This is not the case for the 7 and $11 \mathrm{ML}$ wide wells for which Hanle data are available. It can be seen that for $h v_{\text {exc }}>(11 \mathrm{~h}-1 \mathrm{e}) P\left(\mathrm{~h} v_{\text {exc }}\right)$ is either lower or greater than one half its value for $h v_{\text {exc }}<(1 \mathrm{~h}-1 \mathrm{e})$. We note however that the wider the well the lower the $P\left(h v_{\text {exc }}\right)$ value above the (1lh-le) transition. Such a situation is probably related to an incomplete hole spin relaxation (characterized by a relaxation time $T_{1 \mathrm{~h}}$ ) which might be taken into account in interpretating the data. However the hole relaxation processes involved in these two situations seem to be different, and not related to the location of the llh level with respect to the barrier. Effectively in both cases (type 1 or type II). the llh level lies in a 2 or $3 \mathrm{meV}$ energy interval above or below the barrier and it can be noted that $P\left(h v_{\text {exc }}\right)$ remains constant on a $20 \mathrm{meV}$ energy range above the 
(11h-1e) transition. On the other hand the fact that $P\left(h v_{\text {exc }}\right)$ can be considered constant when the sole hh are excited, would mean that the state of correlation in which the electron-hole pair is created has no repercussion on the spin-flip rate occuring during the relaxation towards the fundamental exciton state, from which the luminescence is recorded. It would then be necessary to consider an exciton relaxation time rather than $T_{1 e}$ and $T_{1 h}$.

To conclude we shall say that the interpretation of the optical pumping results on strained $\operatorname{In}_{x} \mathrm{Ga}_{1-\mathrm{x}} \mathrm{As} / \mathrm{GaAs} \mathrm{QW}$ 's is not so easy as each $\mathrm{QW}$ seems to represent a particular case.

References

[1] Hermann C.,Lampel G. and Safarov V.I.,Annales de Physique(Paris) 10 (1985) 1117-1138.

[2] Miller R.C. and Kleinman D.A.,J.Luminesc, 30 (1985) 520-540.

[3] Bacquet G.,Barrau J., Hassen F., Lauret N. and Massies J.,Superlattices and Microstructures 11 (1992) 495-499.

[4] Quivy-da Silva E.C.F., Chitta V., Toet D., Potemski M., Maan J.C. and Ploog K.,Semicond.Sci.Technol.7 (1992) 1369-1376.

[5] Bandet J., Bacquet G., Fabre F., Frandon J., Taouint R., Planel R. and Le Roux G.,J.Appl.Phys.69 (1991) 2532-2535.

[6] Miller R.C., Kleinman D.A., Nordland W.A. and Gossard A.C.,Phys.Rev.B 22 (1980) 863-871.

[7] Uenoyama T. and Sham L.J.,Phys.Rev.B 42 (1990) 7114-7123.

[8] Vasil'ev A.M., Daiminger F., Straka J., Forchel A., Kochereshko V.P., Sandler G.L. and Uraltsev I.N.,Superlattices and Microstructures 13 (1993) 97-100.

[9] Marie X., Barrau J., Brousseau B., Amand Th., Brousseau M., Rao E.V.K. and Alexandre F.,J.Appl.Phys.69 (1991) 812-815.

[10] Muraki K., Fukatsu S., Shiraki Y. and Ito R.,Appl.Phys.Lett. 61 (1992) 557-559.

[11] Nagle J., Landesman J.P., Larive M., Mottet C. and Bois P.,J.Crystal Growth 127(1993) 550-555.

[12] Hassen F., Bacquet G., Lauret N., Barrau J., Howard L.K. and Dunstan D.J.,Solid State Commun. submitted for publication. 